\title{
QUALITY ASSURANCE AND THE PHILIPPINE EDUCATION SYSTEM: INPUTS FROM FUTURE FILIPINO SCHOOL LEADERS
}

\author{
Oleh \\ Inero V. Ancho \\ Philippine Normal University - Manila \\ ancho.iv@pnu.edu.ph
}

diterima 22 Juni 2019, direvisi 19 Agustus 2019, diterbitkan 31 Agustus 2019

\begin{abstract}
This study involves future education leaders and managers in the Philippines and their conceptual understanding of "quality" in the context of education, the streams of teaching and learning to be specific. Respondents were enrolled in a graduate program in a teacher education institution based in Manila, Philippines and were asked the following: (1) concepts identified with quality; (2) conceptual understanding of quality assurance; (3) quality assurance mechanisms employed in the Philippine education system; and (4) proposed quality assurance mechanisms to uplift the academic achievement of Filipino students. It has been revealed that while future education leaders and managers possess sufficient ideas and knowledge about quality assurance, it is still vital to provide them with technical know-how and discourses on the theoretical-practical connection of quality and students' academic achievement. Quality assurance mechanisms being implemented are considered to be effective in the Philippine education system.
\end{abstract}

\section{Keywords: Quality Assurance, Philippine Education System, Quality, Academic Achievement, Education Leaders}

\section{INTRODUCTION}

Quality as a concept plays an integral role towards achievement of targeted goals and objective. Mechanisms are put in place to ensure that what have been identified as key results areas will be met under existing conditions. While quality is said to be a habit and a way of life, barriers and challenges still exist to some organizations in relation to meeting desired outcomes. Hoy et al. (2000) equates quality as a concept evaluates the educational process to meet the standards. In higher education, keeping and promoting standards is the fundamental goal of quality assurance (Stamoulas, 2006).

In the context of education, quality can be identified in most elements: quality education, quality teachers, quality students, and so on. Quality is being equated to favourable academic outcomes and higher achievement level of students, which is apparently the ultimate goal of 
teaching and learning, thus Laine et al. (2011) insist that "school teaching profession requires the best talents available." Bogue \& Hall (2003) consider it as parallel within measures of accountability and integrity.

Policy makers craft programs and activities in relation to curriculum so students will have a meaningful school life experience. These policies are geared towards preparing the students to be lifelong learner. With these policies at hand, quality education is expected to be evident, given the effective planning, execution, implementation, monitoring, and evaluation of programs and policies.

To be able to meet the greatest determinant of examination performance, the quality of the intake of the school is considered (Bradley and Taylor, 2003). Teachers are being trained and provided with capacity building activities to be able to meet the needs of the profession. Instructional practices are carefully planned and executed along authentic assessment strategies to genuinely capture and assess student performance. This could be further enhanced by providing high quality teacher education (Chong and Ho, 2009).

The dawn of the K-12 curriculum in the Philippines as mandated by RA 1083 is an avenue to strengthen the quest towards quality education in the country. Stakeholders are being challenged to actively take part in preparing Filipino students to be 'globally competitive' individuals, prepared to pursue higher education, venture into entrepreneurship, or be employed.

To achieve the mandates of RA 1083, quality assurance is one critical aspect that needs attention. Mechanisms must be carefully scrutinized to establish alignment with identified goals and objectives, particularly learning outcomes of the students. Stakeholders' roles and accountability are of the highest concerns in ensuring that processes are planned, implemented, and evaluated according to quality standards.

The need to capture the voices of future educational leaders and managers is very timely because it would serve as a mechanism to determine future directions of the Philippine education system. It is crucial to note that these individuals would occupy vital posts in the education sector, local or national scale, and they would be the prime movers of policy-related attempts. The implication also eventually lies on formal and informal training programs offered by higher education institution in preparing these individuals.
This paper is an attempt to capture the voices of Filipino teachers in relation to quality in the context of education. It provides avenues for discussion on their conceptual understanding of quality and quality assurance mechanisms being implemented by the Department of Education (DepEd). Also, this study offers to gather ideas of teachers as front liners of education regarding policies that they have in mind that they think would definitely help raise students' academic achievement.

This study places its significance in advocating the inclusivity of policy planning. Teachers' voices are those from the ground which need to heard and be considered as springboard for discussion on matters concerning quality assurance and student achievement. Almadani, et al (2011) concluded that the development of almost all quality assurance procedures lack research-based inquiries.

Top-to-bottom approach on policy creation would yield favourable outcomes since the experiences and conceptions of teachers are borne out of their own daily endeavour inside the classroom. With this in mind, ideas, perceptions, and notions of future school leaders are deemed significant and crucial.

Eventually, these individuals are poised to assumed leadership and management roles in private and public schools and other education institutions. The kind of leadership they emulate would apparently shape efforts geared toward the achievement of quality education. As Henard and Mitterle (2010) put it, there exists a connection between governance and quality assurance.

\section{METHODOLOGY}

This study involves classroom teachers who are currently pursuing their graduate studies program in a Teacher Education Institution based in Manila, Philippines. Eighteen respondents were asked to complete five-item open ended questions. Generally, research instrument used contained the following items:

\section{A. Write down four words that you identify with the word "quality."}

B.What is your conceptual understanding of quality assurance?

C. What quality assurance mechanisms do you know that are being employed in Philippine Education system? 
D.If you were to craft a policy on quality assurance mechanisms in order to uplift the academic achievement level of Filipino students, what policy would you develop?

The following table presents a summary of respondents:

Qualitative replies were then collected, tabulated, and tallied. Responses were coded to highlight emerging themes, which were eventually interpreted.

For the ethical conduct of research, respondents were asked to sign an informed consent form in relation to their participation of the study. Before each respondent signed the informed consent form, they were given an overview of the nature of the study, its purpose and protocol for the use of collected data. They were also given an assurance that responses gathered would be for the sole use of this study only.

There were 16 female and 2 male respondents with an average of 5.11 years in the teaching profession. All of them are enrolled in a master's level in educational leadership and management in a teacher education institution based in Manila, Philippines.

\section{RESULTS AND DISCUSSION}

This section presents the results and discussion of the study. Each response has been carefully tabulated an analysed to provide thorough investigation of identified research questions.

\section{Quality and related words}

There were 42 unique words that respondents identify with the word "quality". Respondents were asked to write down four words and a bulk of responses relates quality with the following ideas:

Table 1. Ranking of words mostly identified with quality.

\begin{tabular}{|c|c|}
\hline Concept & Rank \\
\hline standard & 1 \\
\hline excellent & 2 \\
\hline value & 3 \\
\hline efficiency & 4 \\
\hline effective & 4 \\
\hline best & 4 \\
\hline
\end{tabular}

The table above sequences words frequently identified with quality. The top response is "standard", followed by "excellent" and "value." It could be gleaned that these words can be categorized as end product, process, or characteristics.

The following words, clustered as end results, are related to quality according to the respondents: product-centered, beneficial, contentment, best, above average, worth, effective, satisfaction, standard, excellent, value, efficiency, and best. Also, the following words were clustered as process in relation to quality: status, functional, aim, and evident.

\section{Quality assurance as a concept}

The respondents were also asked about their conceptual understanding of quality assurance. Analysis of the responses showed that there are tw o classifications on the conceptual respondents' conceptual understanding of quality assurance: as a process and as a measure.

Quality assurance as a process presents practices and performance indicators that reflect the achievement of desired outcomes. Monitoring is also mentioned by respondents under this category along with maintaining what has been identified to be "at par with standards".

The following are the specific responses under this category:

making sure results are best, excellent, or high level

being confident about the output

giving a definite standard

ensuring the system passed the standard

performing beyond the standard

making sure of the production of desired outcome

making sure to put the best you can provide; at par with standards

ensuring that set of goals is being carried in accordance with stands 
monitors quality services rendered

maintaining the standards met

producing the ideal

The second identified cluster views quality assurance as a measure. Concepts under this classification are considered to be conditions and units reflecting observable value or performance. These concepts exhibit characteristics that are critical in nature.

The following are the specific responses under this category:

worth sharing

system is on its best condition

parallelism between objective/goal and performance

standards and criteria

performance satisfaction of one's work

guideline that encompass the totality of your envisioned result

Above-mentioned concepts are those that embody quality practices and treated as evidence when it comes to concrete exhibits of quality.

Quality Assurance Mechanisms and the Philippine Department of Education

The mandate of the Department of Education is successfully achieved given the quality assurance mechanisms being observed. These measures are consistently made consistent of the system, thus a culture of quality is practiced. Respondents were also asked to list down quality assurance mechanisms they know that are being implemented by the Department of Education.

Respondents were able to identify measures being implemented and these could be categorized as those that involve either internal or external participation of persons involved like students, teachers, etc.

External measures include quality certifications like ISO, certification and assessment procedures, and accreditation. These mechanisms are in place to subject an institution to audit, review, and assessment given accepted standards of parameters.

On the other hand, internal measures are those initiated by the institution, within the institution itself. These are attempts at instituting programs, projects and services that are central to achievement of identified goals and objectives. These internal efforts involve daily school operations, along with everyone in the institutions (teachers, students, etc.)

The following are the identified internal quality assurance measures:

salaries and incentives

strategic plan

human resource management strategies (hiring, license, training)

administrative and systemic requirements

standardized test (National Achievement Test, etc.)

academic competitions

student empowerment

The last portion of the study captures perspectives of future educational leaders and managers regarding crafting of policies in order to uplift the academic achievement level of Filipino learners. Respondents were asked on any policy recommendations they would like to craft. This inquiry is done in order to provide avenues for ideas on policy making that would possible contribute to increased achievement level of the students.

Inquiring about possible policy ideas in anchored on pressing issues that need solutions. By coming with an attempt to create a policy, an emerging problem is being recognized, thus policies are crafted to address these issues.

Among quality related policy ideas proposed by the respondents are the following:

strict implementation of strict implementation of the 10-point Agenda of the Goals for Education

raise teacher standards

support on education research and development 
teacher training and strategies

student promotion based on performance

authentic assessment

strengthening QA office

boosting teacher performance

teacher development

catering multiple intelligences

medium of instruction

With the above-mentioned proposed policy ideas, issues and concerns related to quality assurance in the context of education were also uncovered. These include classroom assessment, language use, teacher and student competencies, performance assessment, and others.

Issues and challenges that confront the education sector require proactive solutions and evidence-based approaches. As these problems were recognized, educational leaders and managers are being invited to showcase skills and competence in providing solutions to these issues.

It is a must for an educational leader and manager to be equipped with quality concepts and competencies, thus, it becomes a habit and a way of life. Quality is central to successful achievement of goals, whether in or out of the classroom. The ideas possessed by future educational leaders and managers exhibit prospects for the future: grounded on present issues and established by past experiences.

\section{CONCLUSION}

As future educational leaders and managers pursue higher level of education, they carry with them their own conceptual understanding of quality and quality assurance. These ideas would eventually shape and bring form to the kind of leadership they would exhibit in the future. It is high time that these individuals be provided with theoretical and research-based foundation on quality and quality assurance mechanism to back up with professional practices.

There is a need to familiarize and eventually help students be adept at trends and issues on quality-related concerns in the field of education.
This would give them an advantage to fully realize the role of quality mechanisms in achieving the ultimate goal of teaching and learning: student achievement.

While future educational leaders and managers are exposed to quality assurance mechanisms in the Philippine education system, particularly those implemented by the Department of Education, they also possess promising ideas to contribute to the success of the education process. These ideas may be implemented at the institutional level, while some are deemed considerable in the district, regional, and national levels.

The dawn of K-12 implementation years ago has created an impact on the way future educational leaders and managers view quality. Efforts of the Philippine government in improving quality standards of education in the country have been fruitful as it creates positive consciousness among stakeholders that processes involving teachers, parents, students, and others are central to ensure success of teaching and learning.

Future research could explore how current educational leaders and managers view quality and quality assurance matters in the Philippine education landscape. This could bring opportunities and reflections on the gap with the way key persons address issues on education quality. Perspectives of these individuals would bring concrete understanding on mechanisms being put into place and establish rationale on future directions.

Eventually, marrying the viewpoints of current and future educational leaders about quality efforts would shed light on the gap when it comes to leadership transition, especially in crafting long term quality standards in the context of Philippine education system. These inputs once weaved could pave way to a more sustainable, responsive, and evidence- based quality efforts. 


\section{REFERENCES}

Almadani, K. Reid, N., Rodrigues, S. (2011). Quality Assurance: A Pressing Problem for Education in the $21^{\text {st }}$ Century. Problems of Education in the $21^{\text {st }}$ Century, 32 (9)

Bogue, E. G., \& Hall, K. B. (2003). Quality and accountability in higher education: Improving policy, enhancing performance. Westport, CT: Praeger.

Chong, S. and Ho, P. (2009) 'Quality teaching and learning: a quality assurance framework for initial teacher preparation programmes', Int. J. Management in Education, Vol. 3, Nos. 3/4, pp.302-314.

Hoy, C., Bayne-Jardine, C., Wood, M. (2000). Improving Quality in Education, London: Falmer Press.

Henard, F., \& Mitterle, A. (2010). Governance and quality guidelines in higher education: A review of governance arrangements and quality assurance guidelines. Paris, France: OECD.
Laine, S., Begrstock-Sherrat, E., Lasagna, M. (2011). Improving Teacher Quality, Jossey-Bass, San Fransisco, Wiley.

Stamoulas, A. (2006) 'Greece before the Bologna process: confronting or embracing quality assurance in higher education?' Higher Education Policy, Vol. 19, No. 4, pp.433445 . 